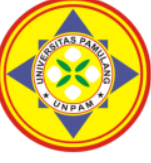

\title{
PENGARUH LINGKUNGAN KERJA FISIK DAN DISIPLIN KERJA TERHADAP KINERJA KARYAWAN PT. PLANETMAS ADIDAYA BOGA
}

\author{
${ }^{1}$ Arvian Setya Pramaswara, ${ }^{2 *}$ Isep Amas Priatna \\ Universitas Pamulang, Tangerang, Banten, Indonesia \\ *dosen01629@unpam.ac.id
}

\begin{abstract}
Abstrak
Penelitian ini bertujuan untuk mengetahui pengaruh secara parsial dan simultan tingkat lingkungan kerja fisik dan disiplin kerja terhadap kinerja karyawan PT Planetmas Adidaya Boga. Metode penelitian yang digunakan bersifat kuantitatif asosiatif, pendekatan ini digunakan untuk mengetahui pengaruh hubungan antara dua variabel atau lebih, dengan teknik sampling yaitu probability sampling dengan hasil perhitungan slovin 85 responden. Hasil penelitian ini adalah lingkungan kerja fisik dan disiplin kerja berpengaruh signifikan terhadap kinerja karyawan dengan persamaan regresi $\mathrm{Y}=20,963+0,305 \mathrm{X} 1+0,271 \mathrm{X} 2$. Nilai koefisien korelasi diperoleh sebesar 0.534 artinya variabel bebas dengan variabel terikat memiliki hubungan yang sedang dengan koefisien determinasi sebesar 6.24\%. Uji hipotesis (uji F) diperoleh nilai Fhitung > Ftabel atau 16.316 > 3.11 dengan demikian $\mathrm{H} 0$ ditolak dan Ha diterima. Artinya terdapat pengaruh signifikan secara simultan antara lingkungan kerja fisik dan disiplin kerja terhadap kinerja karyawan PT Planetmas Adidaya Boga.
\end{abstract}

Kata Kunci: Lingkungan Kerja Fisik, Disiplin Kerja, Kinerja Karyawan

\section{Abstract}

This study aims to determine the effect of partially and simultaneously the level of physical work environment and work discipline on the performance of PT Planetmas Adidaya Boga employees. The research method used is quantitative associative, this approach is used to determine the effect of the relationship between two or more variables, with a sampling technique, namely probability sampling with the results of the calculation of slovin 85 respondents. The results of this study are the physical work environment and work discipline have a significant effect on employee performance with the regression equation $Y=20.963+0.305 X 1+0.271 X 2$. The correlation coefficient value is 0.534 , meaning that the independent variable and the dependent variable have a moderate relationship with a determination coefficient of $6.24 \%$. Hypothesis test ( $F$ test) obtained the value of Fcount > Ftable or 16,316 > 3.11 thus $\mathrm{HO}$ is rejected and Ha is accepted. This means that there is a simultaneous significant effect between the physical work environment and work discipline on the performance of PT Planetmas Adidaya Boga employees.

Keywords: Physical Work Environment, Work Discipline, Employee Performance

\section{PENDAHULUAN}

Pada hakikatnya dalam mencapai suatu tujuan yang maksimal adalah dimulai dari hal yang paling menunjang untuk tercapainya suatu tujuan tersebut, yaitu sumber daya manusia (SDM). Sumber daya manusia adalah individu produktif yang bekerja sebagai penggerak suatu organisasi, pemikir dan perencana untuk mencapai tujuan organisasi, di dalam institusi maupun perusahaan sehingga harus dilatih dan dikembangkan kemampuannya. Tanpa sumber daya manusia perusahaan tidak akan dapat menjalankan usahanya, agar dapat bertahan menghadapi persaingan dan terus menjaga eksistensinya perusahaan harus dapat mengelola sumber daya manusia dengan baik.

Menurut Sutrisno dalam Haeruddin (2016 : 198) "suatu organisasi dikatakan berhasil, jika secara efektif dan efisien dapat mendayagunakan sumber daya terutama karyawan yang ada dengan optimal dan profesional". Keberhasilan suatu organisasi sangat dipengaruhi oleh kinerja individu karyawannya. Peningkatan kinerja karyawan akan membawa kemajuan bagi perusahaan untuk dapat bertahan dalam 
suatu persaingan lingkungan bisnis yang tidak stabil. Menurut Kasmir (2016 :182) "kinerja karyawan adalah hasil kerja dan perilaku kerja yang telah dicapai dalam menyelesaikan tugas- tugas dan tanggung jawab yang diberikan dalam suatu periode tertentu". Standar kinerja diatur dan ditetapkan oleh pemimpin untuk dijadikan tolok ukur karyawan dalam menjalankan tugasnya, untuk mengetahui, apakah kinerja karyawan sudah maksimal atau belum, maka kinerja karyawan perlu dinilai agar dapat mengevaluasi tanggung jawab atas pekerjaan yang sudah diberikan. Menurut Kasmir (2016 : 189) “pengetahuan, kemampuan dan keahlian, rancangan kerja, budaya organisasi, kepuasan kerja, kepribadian, motivasi kerja, gaya kepemimpinan, kepemimpinan, loyalitas, komitmen, lingkungan kerja, dan disiplin kerja merupakan faktor yang mampu memberikan pengaruh pada kinerja karyawan".

Variabel yang mempengaruhi kinerja karyawan dalam penelitian ini adalah variabel lingkungan kerja fisik dan disiplin kerja. Menurut Sedarmayanti (2017 : 26) "lingkungan kerja fisik adalah semua keadaan berbentuk fisik yang terdapat di sekitar tempat kerja yang dapat memengaruhi karyawan baik secara langsung maupun tidak langsung". Suatu kondisi lingkungan kerja dikatakan baik apabila karyawan dapat melaksanakan kegiatan secara optimal, sehat, aman, dan nyaman. Oleh karena itu penentuan dan penciptaan lingkungan kerja fisik yang baik akan sangat menentukan keberhasilan pencapaian tujuan organisasi. Disiplin kerja dimaksud untuk mendidik karyawan agar dapat mematuhi aturan, kebijakan, dan norma yang berlaku di dalam perusahaan sehingga waktu yang digunakan efektif dan efisien untuk mencapai hasil yang optimal untuk perusahaan. Menurut Terry dalam Edy Sutrisno (2019 : 87) “disiplin kerja merupakan alat penggerak karyawan".

Peneliti terdahulu yang dilakukan oleh Syutrika Vergie Rorong (2016) menunjukkan bahwa lingkungan kerja fisik berpengaruh signifikan terhadap kinerja karyawan. Muhamad Ekhsan (2019) menunjukkan bahwa disiplin kerja berpengaruh signifikan terhadap kinerja karyawan. Namun menurut Dewi Fitriani, Nurlaela, dan Dirarini Sudarwad (2018) lingkungan kerja fisik secara parsial tidak berpengaruh terhadap kinerja karyawan.

Objek yang diambil dalam penelitian ini adalah karyawan PT Planetmas Adidaya Boga merupakan usaha yang sedang berkembang di bidang Food and Beverage dengan brand bernama Fish Streat. Hasil data kinerja menunjukkan fluktuatif, dikarenakan kurangnya disiplin karyawan yang setiap tahunnya menurun. Kurang disiplinnya karyawan dapat terjadi karena lingkungan kerja fisik yang belum terealisasi dengan baik dan masih belum tercapai kondisi ideal lingkungan kerja fisik yang diharapkan.

Dengan demikian lingkungan kerja fisik harus memadai untuk kenyamanan karyawan agar termotivasi semangat kerja dan disiplin kerja karyawan juga harus baik. Lingkungan kerja fisik yang baik dan disiplin kerja yang meningkat, maka akan meningkat pula kinerja karyawan agar dapat mencapai tujuan perusahaan.

Berdasarkan penjelasan latar belakang dan perbedaan pendapat dari hasil penelitian terdahulu, maka penulis tertarik untuk melakukan penelitian dengan judul "Pengaruh Lingkungan Kerja Fisik dan Disiplin Kerja Terhadap Kinerja Karyawan PT Planetmas Adidaya Boga".

\section{TINJAUAN PUSTAKA}

1. Kinerja

Menurut Afandi (2018:83) "kinerja adalah hasil kerja yang dapat dicapai oleh seseorang atau kelompok orang dalam suatau perusahaan sesuai dengan wewenang dan tanggung jawab masingmasing dalam upaya pencapaian tujuan organisasi secara legal, tidak melanggar hukum dan tidak bertentangan dengan moral dan etika". Menurut Kasmir (2016:182) “kinerja adalah hasil kerja dan perilaku kerja yang telah dicapai dalam menyelesaikan tugas-tugas dan tanggung jawab yang diberikan dalam 
suatu periode tertentu". Menurut Mangkunegara (2015:67) "kinerja adalah hasil kerja secara kualitas dan kuantitas yang dicapai oleh seorang pegawai dalam melaksanakan tugasnya sesuai dengan tanggung jawab yang diberikan kepadanya". Berdasarkan pengertian menurut Afandi, Kasmir, dan Mangkunegara dapat disimpulkan bahwa kinerja merupakan hasil kerja yang telah dicapai atas keberhasilan tugas dan tanggung jawabnya dalam upaya pencapaian tujuan organisasi atau perusahaan.

\section{Lingkungan Kerja}

Menurut Sedarmayanti dalam Rahmawati (2014:3) "lingkungan kerja adalah keseluruhan alat perkakas dan bahan yang dihadapi, lingkungan sekitarnya dimana seseorang bekerja, metode kerjanya, serta pengaturan kerjanya baik sebagai perseorangan maupun kelompok". Menurut Sunyoto (2013:43) "lingkungan kerja adalah segala sesuatu yang ada disekitar pekerja dan yang dapat mempengaruhi dirinya dalam menjalankan tugas yang dibebankan. Berdasarkan pengertian di atas dapat disimpulkan bahwa lingkungan kerja merupakan keseluruhan yang berada dilingkungan pekerja baik berupa fisik maupun non fisik yang dapat mempengaruhi dirinya dalam menjalankan tugas yang dibebankan.

\section{Disiplin Kerja}

Disiplin kerja merupakan sikap atau perilaku seseorang yang menjalankan segala sesuatu dengan tepat waktu dan patuh pada peraturan perusahaan tempat ia bekerja. Disiplin kerja dapat dilihat sebagai sesuatu yang besar manfaatnya, baik bagi kepentingan perusahaan maupun karyawan. Bagi organisasi adanya disiplin kerja akan menjamin terpeliharanya tata tertib dan kelancaran pelaksanaan tugas, sehingga diperoleh hasil yang optimal. Disiplin yang baik mencerminkan besarnya rasa tanggung jawab seseorang terhadap tugas-tugas yang diberikan kepadanya.

Menurut Hasibuan (2016:143) "kedisiplinan adalah kesadaran atau kesediaan seseorang untuk menaati semua peraturan-peraturan dan normanorma sosial yang berlaku. Kesadaran itu sendiri adalah sikap seseorang yang sukarela untuk menaati semua peraturan dan sadar akan tugas dan tanggung jawabnya sehingga akan mematuhi atau mengerjakan semua tugasnya dengan baik, bukan atas paksaan. Sedangkan kesediaan adalah suatu sikap, tingkah laku dan perbuatan seseorang yang sesuai dengan peraturan perusahaan, baik yang tertulis maupun yang tidak tertulis". Menurut singodimedjo dalam Sutrisno (2016:94) "disiplin kerja adalah sikap kesediaan dan kerelaan seseorang untuk mematuhi dan mentaati normanorma peraturan yang berlaku disekitarnya".

Menurut Mangkunegara

(2016:129) "disiplin kerja adalah pelaksanaan manajemen dalam meneguhkan pedoman dan peraturan perusahaan". Berdasarkan pengertian menurut Hasibuan, Singodimedjo dan Mangkunegara dapat disimpulkan bahwa disiplin kerja merupakan bentuk kesadaran, sikap, dan perilaku seseorang untuk mentaati tata tertib perusahaan, kebijakan, serta norma-norma yang berlaku di perusahaan.

\section{METODE}

Penelitian ini dilaksanakan di PT Planetmas Adidaya Boga yang beralamat di Jalan Merawan No. 14 Kelurahan Pangkalan Jati, Kecamatan Cinere, Kota Depok, Jawa Barat. Waktu Penelitian ini dilaksanakan selama 5 (lima) bulan yang dimulai dari bulan November 2020 - Maret 2021.

Populasi dalam penelitian populasinya adalah karyawan PT Planetmas Adidaya Boga yang berjumlah 112 karyawan, teknik pengambilan sampel memakai rumus slovin dengan tingkat galat $5 \%$ didapat responden sebanyak 85 , Teknik 
pengumpulan data menggunakan penyebaran kuesioner, wawancara dan observasi. Teknik pengolahan data dengan menggunakan uji instrumen data, uji prasyarat data dan uji statistic.

\section{HASIL DAN PEMBAHASAN}

a. Pengaruh Lingkungan Kerja Fisik $\left(X_{1}\right)$ terhadap Kinerja $(\mathrm{Y})$

Berdasarkan hasil penelitian ini didapatkan bahwa variabel Lingkungan Kerja Fisik (X1) memiliki pengaruh terhadap Kinerja (Y) pada karyawan PT Planetmas Adidaya Boga. Pengaruh lingkungan kerja fisik terhadap kinerja karyawan dapat dijelaskan dengan beberapa faktor. Indikator lingkungan kerja yang memiliki nilai terendah pada pernyataan Musik di tempat kerja saya tidak mengganggu pekerjaan" dengan rata-rata nilai 3.59. Hal ini berarti playlist musik yang telah di tentukan oleh perusahaan itu tidak sesuai dengan minat dari karyawan, sebaiknya perusahaan memberikan kebebasan kepada karyawan dalam memilih playlist musik yang sesuai dengan keinginan, namun di berikan arahan untuk memilih playlist musik yang tidak mengganggu jalannya operasional.

Hasil penelitian ini, diperoleh nilai persamaan regresi $\mathrm{Y}=25,902+0,406 \mathrm{X}$ koefisien korelasi sebesar 0.499 artinya kedua variabel mempunyai tingkat pengaruh yang sedang. Uji hipotesis diperoleh nilai $\mathrm{t}$ hitung $>\mathrm{t}$ tabel atau (3.357 > 1.989), hal ini diperkuat dengan probability significancy $0.000<0.05$, dengan demikian $\mathrm{H} 0$ ditolak dan H1 diterima artinya terdapat pengaruh yang signifikan secara parsial antara lingkungan kerja fisik terhadap kinerja karyawan pada PT Planetmas Adidaya Boga.

b. Pengaruh Disiplin Kerja $\left(X_{2}\right)$ terhadap Kinerja (Y)

Berdasarkan hasil penelitian ini didapatkan bahwa variabel Disiplin Kerja (X2) memiliki pengaruh terhadap Kinerja (Y) pada karyawan PT Planetmas Adidaya Boga. Pengaruh disiplin kerja terhadap kinerja karyawan dapat dijelaskan dengan beberapa faktor. Variabel disiplin kerja yang mendapatkan nilai rata-rata terendah ada pada indikator taat terhadap peraturan lainnya pernyataan nomor 8 yaitu saya menjaga tingkah laku sesuai norma yang berlaku, seperti bersikap jujur atau memegang amanah yang diberikan dengan mean sebesar 4.06. Hal ini berarti bahwa sebaiknya karyawan harus lebih bisa menjaga tingkah laku, taat terhadap aturan perusahaan, bersikap jujur dan dapat memegang amanah yang di berikan agar perusahaan dapat memberikan kepercayaan kepada karyawan itu sendiri.

Hasil penelitian ini, diperoleh nilai persamaan regresi $\mathrm{Y}=24,967+0,520 \mathrm{X}$ koefisien korelasi sebesar 0.432 artinya kedua variabel mempunyai tingkat pengaruh yang sedang. Uji hipotesis diperoleh nilai $\mathrm{t}$ hitung $>\mathrm{t}$ tabel atau $(2.011>1.989)$, hal ini diperkuat dengan probability significancy $0.000<0.05$, dengan demikian $\mathrm{H} 0$ ditolak dan $\mathrm{H} 1$ diterima artinya terdapat pengaruh yang signifikan secara parsial antara disiplin terhadap kinerja karyawan pada PT Planetmas Adidaya Boga.

c. Pengaruh Lingkungan Kerja $\left(X_{1}\right)$ dan Disiplin kerja (X2) Secara Simultan Terhadap Kinerja karyawan (Y)

Berdasarkan hasil penelitian ini didapatkan bahwa variabel lingkungan kerja (X1) dan variabel disiplin kerja (X2) memiliki pengaruh terhadap Kinerja (Y) pada karyawan PT Planetmas Adidaya Boga. Kinerja karyawan dapat dijelaskan dengan beberapa faktor. variabel kinerja yang mendapatkan nilai rata-rata terendah ada pada indikator jumlah pekerjaan pernyataan nomor 1 yaitu saya mampu mencapai target pekerjaan yang diberikan perusahaan.dengan mean sebesar 4.06. Hal ini berarti bahwa sebaiknya perusahaan melakukan evaluasi mengenai target pekerjaan, agar target ini tidak terlalu membebani karyawan dalam melakukan 
pekerjaannya, akan lebih baik bila perusahaan memberikan pekerjaan yang sesuai dengan deskjob pekerjaannya masing-masing

Hasil penelitian ini, diperoleh nilai persamaan regresi $Y=20,963+0,305 X 1$ $+0,271 X 2$ koefisien korelasi sebesar 0.534 artinya hubungan antara X1 dan X2 terhadap $Y$ secara simultan masuk dalam kategori sedang. Uji hipotesis secara simultan diperoleh nilai $\mathrm{F}$ hitung $>\mathrm{F}$ tabel atau $(16.316>3.11)$, hal ini diperkuat dengan probability significancy $0.000<0.05$, dengan demikian $\mathrm{H} 0$ ditolak dan $\mathrm{H} 1$ diterima artinya terdapat pengaruh yang signifikan secara simultan antara lingkungan kerja dan disiplin terhadap kinerja karyawan pada PT Planetmas Adidaya Boga.

\section{KESIMPULAN DAN SARAN \\ Kesimpulan}

Berdasarkan pembahasan dan hasil analisis yang telah diuraikan dalam bab sebelumnya mengenai Pengaruh Lingkungan Kerja Fisik dan Disiplin Kerja Terhadap Kinerja Karyawan PT Planetmas Adidaya Boga dapat disimpulkan bahwa :

1. Berdasarkan pengujian hipotesis secara parsial (Uji t) yang telah dianalisis, maka dapat diketahui bahwa Lingkungan Kerja Fisik terhadap Kinerja Karyawan PT Planetmas Adidaya Boga berpengaruh signifikan. Hal ini dikarenakan thitung > ttabel, dimana thitung sebesar 3,357 dibanding ttabel 1,989. Artinya Ho ditolak dan H1 diterima.

2. Berdasarkan pengujian hipotesis secara parsial (Uji t) yang telah dianalisis, maka dapat diketahui bahwa Disiplin Kerja terhadap Kinerja Karyawan PT Planetmas Adidaya Boga berpengaruh signifikan. Hal ini dikarenakan thitung $>$ ttabel, dimana thitung sebesar 2,011 dibanding ttabel 1,989. Artinya Ho ditolak dan $\mathrm{H} 1$ diterima.

3. Berdasarkan pengujian hipotesis secara simultan (Uji F) yang telah dianalisis, maka dapat diketahui bahwa terdapat pengaruh yang signifikan antara
Lingkungan Kerja Fisik dan Disiplin Kerja secara bersama-sama terhadap Kinerja Karyawan PT Planetmas Adidaya Boga. Hal ini dikarenakan nilai Fhitung $>$ Ftabel dimana Fhitung sebesar 16,316 dibanding Ftabel sebesar 3.11. Artinya Ha diterima dan H0 ditolak.

\section{Saran}

Berdasarkan penelitian dan pengamatan pada PT Planetmas Adidaya Boga, maka saran-saran yang dapat diberikan adalah sebagai berikut:

1. Lingkungan kerja fisik

Berdasarkan hasil dari kesimpulan menunjukan bahwa nilai dari pernyataan responden yang paling kecil yaitu "Musik di tempat kerja saya tidak mengganggu pekerjaan" dengan ratarata nilai 3.59. Dikarenakan nilainya paling kecil, ini menunjukan bahwa playlist musik yang telah di tentukan oleh perusahaan itu tidak sesuai dengan minat dari karyawan, sebaiknya perusahaan memberikan kebebasan kepada karyawan dalam memilih playlist musik yang sesuai dengan keinginan, namun di berikan arahan untuk memilih playlist musik yang tidak mengganggu jalannya operasional.

2. Disiplin kerja

Berdasarkan hasil dari kesimpulan menunjukan bahwa nilai dari pernyataan responden yang paling kecil yaitu "Saya menjaga tingkah laku sesuai norma yang berlaku, seperti sikap jujur atau memegang amanah yang di berikan" dengan rata-rata nilai 4,06. Dikarenakan nilainya paling kecil, dalam hal ini sebaiknya karyawan harus lebih bisa menjaga tingkah laku, taat terhadap aturan perusahaan, bersikap jujur dan dapat memegang amanah yang di berikan agar perusahaan dapat memberikan kepercayaan kepada karyawan itu sendiri.

3. Kinerja karyawan

Berdasarkan hasil dari kesimpulan menunjukan bahwa nilai pernyataan responden yang paling kecil yaitu "Saya mampu mencapai target pekerjaan yang 
telah di berikan perusahaan" dengan nilai rata-rata 4.06. Dikarenakan nilainya paling kecil, dengan hasil ini sebaiknya perusahaan melakukan evaluasi mengenai target pekerjaan, agar target ini tidak terlalu membebani karyawan dalam melakukan pekerjaannya, akan lebih baik bila perusahaan memberikan pekerjaan yang sesuai dengan deskjob pekerjaannya masing-masing.

\section{DAFTAR PUSTAKA}

Ahmad, A., \& Syaiful, B. (2020). Pengaruh Kepemimpinan Motivasi dan Disiplin Kerja Terhadap Kinerja Karyawan. Jurnal Ilmiah Magister Manajemen 3(2) 2623-2634.

Amas, I., \& Ariska, R. (2021). Pengaruh Disiplin Kerja dan Motivasi Kerja terhadap Kinerja Pegawai pada Kota Administrasi Jakarta Selatan. Management Studies and Entrepreneurship Journal (MSEJ), 2(1), 48-58.

Dewi, F., Nurlaela, \& Dirarini, S., (2018). Pengaruh Lingkungan Kerja Fisik, Lingkungan Kerja Non Fisik, Dan Disiplin Kerja Terhadap Kinerja Pegawai Guru SMK Negeri 1 Manokwari. Jurnal Manajemen Bisnis, $1,(1)$.

Fahmi, Irham. (2012). Analisis Laporan Keuangan. Bandung: Alfabeta.

Ghozali, Imam. (2012). Aplikasi Analisis Multivariate dengan Program IBM SPSS. Yogyakarta: Universitas Diponegoro.

Ghozali, Imam. (2016). Aplikasi Analisis Multivariete Dengan Program IBM SPSS 23. Edisi 8. Cetakan ke VIII. Semarang : Badan Penerbit Universitas Diponegoro

Handoko T. Hani. (2014). Manajemen Personalia dan Sumber Daya Manusia. Edisi 2. Yogyakarta: BPFE.

Handoko T. Hani. (2015). Manajemen. Edisi 2. Yogyakarta: BPFE.

Hasibuan, Malayu S.P. (2016). Manajemen Sumber Daya Manusia. Edisi Revisi. Jakarta: Penerbit PT Bumi Aksara.
Karlina, D. (2018). Hubungan Komunikasi Interpersonal, Disiplin Kerja Dan Lingkungan Kerja Terhadap Kinerja Pegawai Kantor Pusat LPP TVRI. JENIUS (Jurnal Ilmiah Manajemen Sumber Daya Manusia), 1(2).

Kasmir. (2016). Manajemen Sumber Daya Manusia. Jakarta: PT. Raja Grafindo Persada.

Komarudin, K. (2018). Pengaruh Lingkungan Kerja Terhadap Kinerja Karyawan Pada PT. Pos Indonesia Depok. JENIUS (Jurnal Ilmiah Manajemen Sumber Daya Manusia), 1(3).

Kristianti, L. S., Affandi, A., Nurjaya, N., Sunarsi, D., \& Rozi, A. (2021). Pengaruh Motivasi Dan Disiplin Kerja Terhadap Kinerja Pegawai Pada Dinas Pariwisata Purwakarta. Jurnal Ilmiah PERKUSI, 1(1), 101-109.

Mochamad, K., (2020). Pengaruh Motivasi Kerja, Lingkungan Kerja Fisik dan Disiplin Kerja Terhadap Prestasi Kerja Karyawan Pada CV. Pratama Lamongan. Jurnal Ekonomi Mahasiswa, 1(2).

Mogi, A. (2018). Pengaruh Kompetensi Guru, Motivasi Guru Dan Lingkungan Sekolah Terhadap Hasil Belajar Siswa Sma Tunas Indonesia Bintaro. JENIUS (Jurnal Ilmiah Manajemen Sumber Daya Manusia), 1(2).

Muhamad, E. (2019). Pengaruh Motivasi dan Disiplin Kerja terhadap Kinerja Karyawan. Jurnal Ekonomi dan Kewirausahaan, 13(1), 1978-2586.

Muharmansyah, \& Handri, A., S. (2020). .Pengaruh Disiplin Kerja terhadap Kinerja Karyawan pada PDAM Tirtanadi IPA Limau Manis. Jurnal Studi Manajemen, 2(1), 2685-631X.

Nurjaya, N., Affandi, A., Ilham, D., Jasmani, J., \& Sunarsi, D. (2021). Pengaruh Kompetensi Sumber Daya Manusia Dan Kemampuan Pemanfaatan Teknologi Terhadap Kinerja Aparatur Desa Pada Kantor Kepala Desa Di Kabupaten Gunungkidul, Yogyakarta. JENIUS (Jurnal Ilmiah 
Manajemen Sumber Daya Manusia), 4(3), 332-346.

Paramarta, V., Dewi, R. R. V. K., Rahmanita, F., Hidayati, S., \& Sunarsi, D. (2021). Halal Tourism in Indonesia: Regional Regulation and Indonesian Ulama Council Perspective. International Journal of Criminology and Sociology, 10, 497-505.

Patricia, M., S., \& Silvya, L., M. (2014). Pengaruh Pelatihan Kerja, Motivasi, dan Disiplin Kerja Terhadap Kinerja Karyawan Pada PT. Bank Perkreditan Rakyat Dana Raya. Jurnal EMBA (2014) 2(4), 2303-1174.

Romdonih, F. (2018). Pengaruh Lingkungan Kerja Terhadap Kepuasan Kerja Pegawai Pada Pusat Pendidikan Dan Pelatihan (Pusdiklat) Perdagangan Depok. JENIUS (Jurnal Ilmiah Manajemen Sumber Daya Manusia), 1(2).

Sedarmayanti. (2011). Tata Kerja dan Produktifitas Kerja. Bandung: CV. Mandar Maju.

Sugiyono. (2010). Metode Penelitian Kuantitatif Kualitatif \& RND. Bandung: Alfabeta.

Sugiyono. (2015). Statistik Untuk Penelitian. Bandung: Alfabeta.
Sugiyono. (2019). Metode Penelitian Kuantitatif Kualitatif \& RND. Bandung: Alfabeta.

Suryani, N. L. (2018). Pengaruh Motivasi Terhadap Prestasi Pegawai Pada Pusdiklat Tenaga Administrasi Kementerian Agama RI CiputatTangerang. JENIUS (Jurnal Ilmiah Manajemen Sumber Daya Manusia), 1(3).

Sutrisno, E. (2016). Manajemen Sumber Daya Manusia. Jakarta: Prenadamedia Group.

Syutrika, V., R., (2016). Pengaruh Lingkungan Kerja Fisik Terhadap Kinerja Karyawan pada PT. Bank Negara Indonesia Kantor Wilayah Manado. Jurnal EMBA, 4, (1).

Tri, W. (2017). Pengaruh Stres Kerja Terhadap Kinerja Karyawan (Studi Pada Karyawan Majalah. Jurnal Ilmiah Prodi Manajemen Universitas Pamulang, 4(2).

Yuli, S. (2013). Pengaruh Kompensasi dan Motivasi Kerja Terhadap Kinerja Karyawan Pada PT. Tunas Hijau Samarinda. e-Journal Administrasi Bisnis, 1(1) 0000-0000. 